\title{
Development of calcium phosphate based bioceramics
}

\author{
AMIT SINHA*, A INGLE ${ }^{\dagger}$, K R MUNIM ${ }^{\ddagger}$, S N VAIDYA ${ }^{\dagger \dagger \dagger}$, B P SHARMA and \\ A N BHISEY $\mathbf{Y}^{\dagger}$ \\ Powder Metallurgy Division, Bhabha Atomic Research Centre, Vashi Complex, Navi Mumbai 400 705, India \\ ${ }^{\dagger}$ Cancer Research Institute, Dr Ernest Borges Marg, Parel, Mumbai 400 012, India \\ ${ }^{\ddagger}$ Medical Division, ${ }^{\dagger \dagger}$ High Pressure Physics Division, Bhabha Atomic Research Centre, Mumbai 400 085, India
}

MS received 1 August 2001; revised 26 September 2001

\begin{abstract}
Two bioceramics (Ca-P-O glass and A-W glass ceramic) were produced using conventional methods of ceramic technology. X-ray powder diffraction patterns were used for identifying the phases and 3point bend test was carried out for the determination of fracture strength of the bioceramics. Biocompatibility of both ceramics was evaluated using animal model experiments. Histological studies showed that A-W glass ceramic implanted in the tibia of rat formed an intimate contact with newly grown bone and provided enough strength to the bone to bear the animal weight. Implants made of $\mathrm{Ca}-\mathrm{P}-\mathrm{O}$ glass was almost fully resorbed and was replaced by new bone. The implants made of both the bioceramics were biocompatible and did not exhibit any kind of adverse effect to the surrounding tissues.
\end{abstract}

Keywords. Bioceramic; calcium phosphate; hydroxyapatite; wollastonite; biocompatibility.

\section{Introduction}

Human bone is a composite material made up of collagen and calcium phosphate mineral. The mineral phase of bone comprises $60-70 \%$ of total dry bone weight. Bone mineral is an apatitic calcium phosphate containing carbonate and small amounts of sodium, magnesium, fluorine and other trace elements. The submicroscopic crystal of calcium phosphate in bone resembles the crystal structure of hydroxyapatite (HA). The bone contains carbonated hydroxyapatite having 4-6\% carbonate by weight, called dahllite, which is assigned a formula of (McConnell 1960; LeGeros et al 1967)

$$
\mathrm{Ca}_{3.8}\left(\mathrm{HPO}_{4}\right)_{0.7}\left(\mathrm{PO}_{4}\right)_{4 \cdot 5}\left(\mathrm{CO}_{3}\right)_{0.7}(\mathrm{OH})_{1 \cdot 3 .} \text {. }
$$

In last two decades, remarkable advances in the field of biomaterials have led to the development of bioglasses and bioceramics of various compositions for bone repair and prostheses applications. Hydroxyapatite (HA), $\beta$-tricalcium phosphate $(\beta$-TCP) and their composites are widely used due to their good biocompatibility and osteointegrative properties (Ritter 1997; Suchanek and Yoshimura 1998).

Bioglasses are an important class of biomaterials, which are prepared from a mixture of silica, alumina, magnesia, calcium oxide, sodium oxide, and phosphorous oxide. Hench and co-workers (Hench 1991) have extensively studied ternary phases of these oxides containing

\footnotetext{
*Author for correspondence
}

some $\mathrm{P}_{2} \mathrm{O}_{5}$ and evaluated the biocompatibility of the quenched glasses of various compositions. The bioactivity of bioglass results from the formation of hydroxyapatite layer on the surface. In addition, calcium phosphate based glasses prepared from $\mathrm{CaO}$ and $\mathrm{P}_{2} \mathrm{O}_{5}$ also exhibit biocompatibility. Different calcium phosphates exhibit widely different resorption properties. The resorption property of calcium phosphates depends on $\mathrm{Ca} / \mathrm{PO}_{4}$ ratio, degree of crystallinity and crystal structure. Chin et al (1996) reported the development of resorbable $\mathrm{Ca}-\mathrm{P}-\mathrm{O}$ glass prepared from $\mathrm{CaO}$ and $\mathrm{P}_{2} \mathrm{O}_{5}$ for tooth and bone implant applications. In the present study, a highly resorbable $\mathrm{Ca}-\mathrm{P}-\mathrm{O}$ glass was prepared and this was evaluated for its biocompatibility.

The resorption rate of $\beta$-TCP is higher as compared to $\alpha$-TCP and highly crystalline, sintered HA (Fernandez et al 1999). When the implant is made of HA, new bone starts to form adjacent to the implant with a mineral content the same as in the physiologically mature bone. However, the biomaterial based on HA alone is not suitable for load bearing applications due to lower mechanical strength of HA. For load bearing applications, implants of bioinert materials such as titanium, stainless steel, and titanium-vanadium alloys are used. These materials are generally coated with hydroxyapatite or bioglass for improving the biocompatibility and tissue growth surrounding them. Alternatively, bioceramics, which are composites of HA and a hard ceramic phase can be used as a replacement of bone in the load bearing sections. Partially resorbable sintered porous ceramic consisting of HA and $\beta$-TCP as well as HA-wollastonite 
(A-W) glass ceramic containing $\mathrm{HA}$ and wollastonite phases have been suggested for bone augmentation (Nakamura et al 1985; Jianguo et al 1994). In the present investigation, compacts of $\mathrm{A}-\mathrm{W}$ glass ceramic were also prepared and studied for their biocompatibility.

\section{Experimental}

\subsection{Preparation of $\mathrm{Ca}-\mathrm{P}-\mathrm{O}$ glass}

The $\mathrm{Ca}-\mathrm{P}-\mathrm{O}$ glass having a composition of $\mathrm{CaO} /(\mathrm{CaO}+$ $\left.\mathrm{P}_{2} \mathrm{O}_{5}\right)=0.33$ (by weight) was prepared using reagent grade calcium carbonate and phosphoric acid (liquid, $85 \%$ ) as starting compounds. The selected composition of $\mathrm{Ca}-\mathrm{P}-\mathrm{O}$ glass corresponds to a eutectic composition of the binary $\mathrm{CaO}-\mathrm{P}_{2} \mathrm{O}_{5}$ system. Calcium carbonate was mixed with phosphoric acid and minimum amount of distilled water in a beaker and the mixture was stirred to make a homogeneous slurry. The slurry was dried under an infrared lamp for $6 \mathrm{~h}$. The resulting dried mixture was melted at $1100^{\circ} \mathrm{C}$ for $3 \mathrm{~h}$ in an alumina crucible under atmospheric pressure. The melt was quenched by pouring it into a graphite mould, resulting in the formation of bulk glass. The glass was broken into pieces in the graphite mould by applying mechanical energy with the help of a sharp tool. The $\mathrm{Ca}-\mathrm{P}-\mathrm{O}$ glass pieces obtained were crushed to produce a powder having particle size below $44 \mu \mathrm{m}$. The powder was compacted using a uniaxial hydraulic press at a pressure of $70 \mathrm{MPa}$ using stearic acid as die lubricant. Since the material has a glass transition temperature $\left(T_{\mathrm{g}}\right)$ of $600^{\circ} \mathrm{C}$ (Chin et al 1996), it is generally sintered at a temperature above $T_{\mathrm{g}}$ to obtain a solid body having interconnected porosity. The green compacts were heated at a rate of $5^{\circ} \mathrm{C} / \mathrm{min}$ and sintered under static air at $610^{\circ} \mathrm{C}$ for $2 \mathrm{~h}$ to obtain porous block of $\mathrm{Ca}-\mathrm{P}-\mathrm{O}$ glass. The sintered blocks were then subjected to a crystallization-annealing at $680^{\circ} \mathrm{C}$ for $3 \mathrm{~h}$ and finally at $800^{\circ} \mathrm{C}$ for $3 \mathrm{~h}$.

\subsection{Preparation of A-W glass ceramic}

A-W glass ceramic powder having a composition of MgO: 4.6, $\mathrm{CaO}: 44.9, \mathrm{SiO}_{2}: 34 \cdot 2, \mathrm{P}_{2} \mathrm{O}_{5}: 16 \cdot 3$ and $\mathrm{CaF}_{2}$ : 0.5 (in weight \%) was prepared. $\mathrm{AR}$ grade $\mathrm{MgO}$, $\mathrm{CaCO}_{3} \cdot 2 \mathrm{H}_{2} \mathrm{O}, \mathrm{CaHPO}_{4} \cdot 2 \mathrm{H}_{2} \mathrm{O}$ and $\mathrm{CaF}_{2}$ were used as starting materials for the preparation of the glass ceramic. The starting powders were thoroughly mixed in a pot mill and subjected to calcination at $1000^{\circ} \mathrm{C}$ for $10 \mathrm{~h}$. The calcined powder was melted at $1450^{\circ} \mathrm{C}$ for $2 \mathrm{~h}$ followed by pouring the melt in a graphite mould. The glass obtained was crushed into powder having a particle size below $44 \mu \mathrm{m}$. The powder was compacted using a uniaxial hydraulic press at a pressure of $70 \mathrm{MPa}$, and sintered at $1050^{\circ} \mathrm{C}$ for $3 \mathrm{~h}$ under static air to produce high strength glass ceramic.
XRD patterns of $\mathrm{Ca}-\mathrm{P}-\mathrm{O}$ glass and $\mathrm{A}-\mathrm{W}$ glass ceramics were taken using $\mathrm{CuK}_{\alpha}$ radiation at a scan rate of $2.5 \% \mathrm{~min}$ for identification of phases. A Philips diffractometer (Model PW-1710) was employed for recording the patterns.

The mechanical properties of biomaterials are generally characterized in terms of their fracture strength, compressive strength, bending strength, and fracture toughness. In the present study, fracture strength of the materials was measured by carrying out 3-point bend test. The test was carried out using an Instron floor standing screw driven machine (Model No. 1185) at a crosshead speed of $0.5 \mathrm{~mm} / \mathrm{min}$. The fracture strength $(S)$ was calculated using the flexure stress formula (Engin and $\mathrm{Ta}^{\circ}$ 2000)

$$
S=(3 P L) / 2 b d^{2},
$$

where $P$ is the fracture load in $\mathrm{kg}, L$ the span length, $b$ the width of the sample and $d$ the thickness of the sample in millimeter. Samples having dimensions $40 \times 4 \times 8 \mathrm{~mm}$ were used for bend test.

\subsection{Animal experimentation}

Two 7-8 months old random bred Sprague Dawley rats weighing $\sim 250 \mathrm{~g}$ were used in this study. They were maintained under standard condition: $22 \pm 2^{\circ} \mathrm{C}, 45 \pm 10 \%$ relative humidity and $12 \mathrm{~h}$ light/12 h dark cycle each day. These animals were fed standard laboratory pelleted diet and drinking water ad libitum. These animals were anaesthetized by intraperitoneal injection of Avertin, Sigma Aldrich (10 g of 2,2,2 tribromoethanol) dissolved with $10 \mathrm{ml}$ of 2-methyl-2-butanol as a stock solution and $2.5 \mathrm{ml}$ of stock solution again diluted with $100 \mathrm{ml}$ of $0.9 \%$ saline to make a working solution. This working solution was injected at the rate of $0.015 \mathrm{ml}$ per $\mathrm{g}$ of body weight.

2.3a Surgical procedures: After achieving surgical anaesthesia, rats were immobilized on their back and longitudinal skin incision of $1 \mathrm{~cm}$ each were given at the level of tibial crest on medial aspect of the leg. Tibial bone was exposed by blunt dissection. Holes of $2 \times 1 \mathrm{~mm}$ were drilled from medial aspect using high-speed dental burr under continuous cooling by distilled water. After making appropriate holes the wound was soaked by sterile cotton gauge in order to arrest bleeding and to soak the excess water. Implants of A-W glass ceramic and $\mathrm{Ca}-\mathrm{P}-$ $\mathrm{O}$ glass were inserted in holes of left and right tibias respectively. After the implants were inserted, soft tissues were sutured in separate layers by using cotton thread. To combat the secondary infection, antibiotic pefloxacin was given in drinking water for 5 days at the dose rate of $10 \mathrm{mg}$ per $\mathrm{kg}$. The implants were assessed by X-ray radiography 2 and 6 months after the operative procedure.

2.3b Histological procedures: Rats were sacrificed by overdose of intraperitoneal injection of Avertin and tibias 
were excised removing the surrounding tissues. Tibia bone pieces were fixed in $10 \%$ formal saline, decalcified by Versenate method and processed for routine $\mathrm{H} \& \mathrm{E}$ staining (Coolidge and Howard 1979).

\section{Results and discussion}

The XRD pattern of as prepared $\mathrm{Ca}-\mathrm{P}-\mathrm{O}$ glass powder is shown in figure 1a. The pattern exhibits weak diffraction lines superposed on a broad hump extending from 20 to $40^{\circ}(2 \theta)$, indicating the amorphous nature of the powder. On crystallization-annealing at $680^{\circ} \mathrm{C}$ for $3 \mathrm{~h}$ and finally at $800^{\circ} \mathrm{C}$ for $3 \mathrm{~h}, \mathrm{Ca}-\mathrm{P}-\mathrm{O}$ glass shows diffraction lines due to crystalline phases and a broad hump due to the presence of residual amorphous phase (figure $1 \mathrm{~b}$ ). The diffraction lines in the pattern reveal the presence of $\beta$ $\mathrm{Ca}_{2} \mathrm{P}_{2} \mathrm{O}_{7}$ and $\mathrm{CaP}_{2} \mathrm{O}_{6}$. The phase composition of the glass matches with that reported by Chin et al (1996).

The composition of the A-W glass ceramic had been chosen so that it would evolve into a composite of hydroxyapatite and wollastonite, $\mathrm{CaSiO}_{3}$ (Nakamura et al 1985). These phases are seen in the XRD pattern of the glass-ceramic (figure 2).

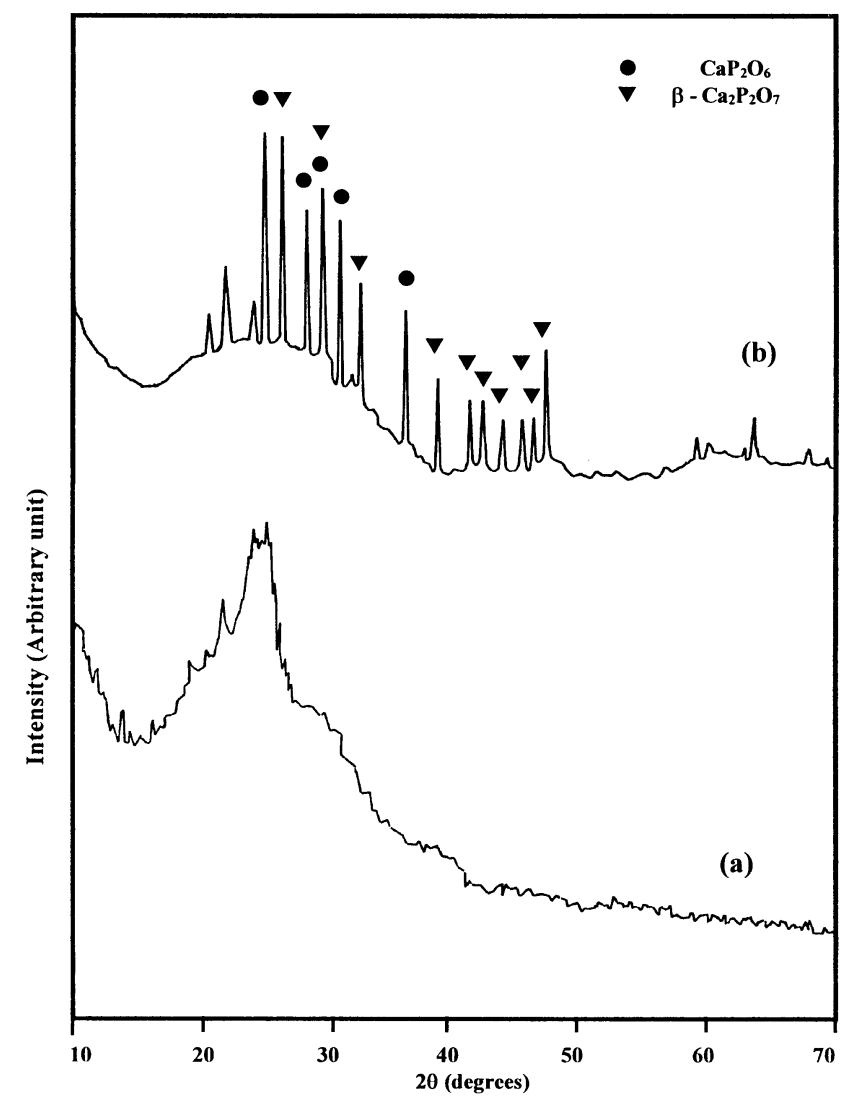

Figure 1. XRD pattern of $\mathrm{Ca}-\mathrm{P}-\mathrm{O}$ glass: (a) as prepared powder and (b) crystallization-annealed at $680^{\circ} \mathrm{C}$ for $3 \mathrm{~h}$ and finally at $800^{\circ} \mathrm{C}$ for $3 \mathrm{~h}$.
The A-W glass ceramic has bending and compressive strength higher than that of dense $\mathrm{HA}$ as well as $\mathrm{Ca}-\mathrm{P}-\mathrm{O}$ glass (Nakamura et al 1985; Chin et al 1996). We find that the fracture strength obtained from 3-point bend test for A-W glass ceramic, which is $12 \mathrm{MPa}$, is higher than that of $\mathrm{Ca}-\mathrm{P}-\mathrm{O}$ glass, which is $8 \mathrm{MPa}$.

\subsection{Bio implantation}

There was no sign of infection at the site of implants in both the animals as evidenced by absence of swelling or lameness of the leg up to six months after operating the animals. X-ray radiograph of left tibia, taken after 2 months of implantation, revealed a piece of A-W implant (arrow) in situ with properly healed wound as evidenced by the absence of swelling or formation of callous at the place of implantation (figure 3a). The implant was also assessed after six months of operation, which also showed that the A-W block is well in place and that there is no abnormality of the bone (figure $3 \mathrm{~b}$ ). X-ray radiograph of $\mathrm{Ca}-\mathrm{P}-\mathrm{O}$ glass implanted tibia, taken after 2 months of implantation, did not reveal the implanted $\mathrm{Ca}-\mathrm{P}-\mathrm{O}$ glass block but showed proper healing without any deformity or callous growth at the site of implant (figure 4a). This indicates total resorption of $\mathrm{Ca}-\mathrm{P}-\mathrm{O}$ glass along with new bone growth. This group was again assessed radiographically after six months where similar changes were noticed (figure 4b). Upon sacrificing the animals, no sign of infection or chronic inflammation was evident at the site of operation. Second set of X-rays in both implants, also revealed the same changes and that no deterioration had occurred at the site of the implants.

Histology section of bone implanted with A-W glass ceramic is shown in figure 5. It showed that the implanted material formed contact with newly grown bone tissues during the process of healing of the breached bone. From

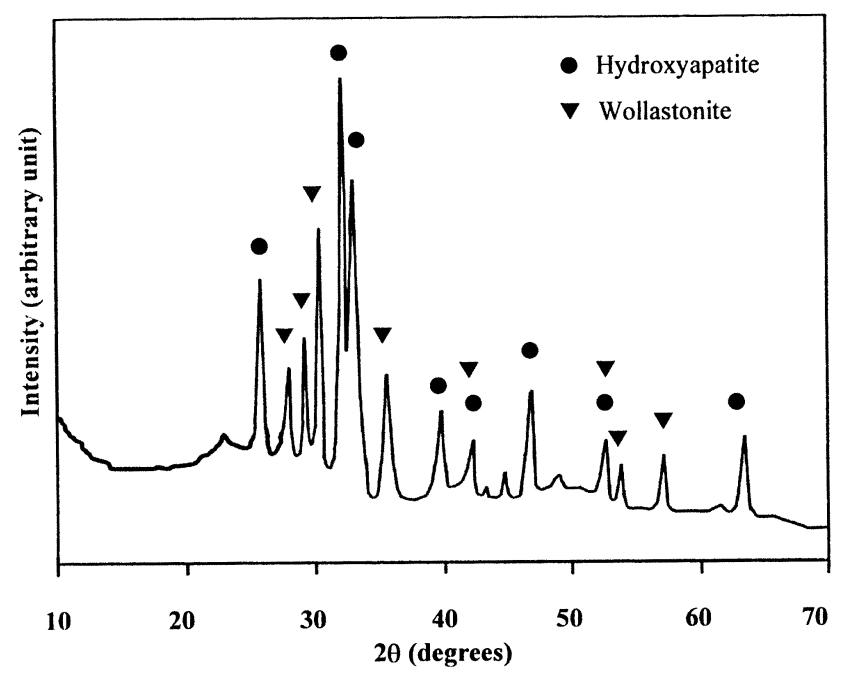

Figure 2. XRD pattern of $A-W$ glass ceramic sintered at $1050^{\circ} \mathrm{C}$ for $3 \mathrm{~h}$. 

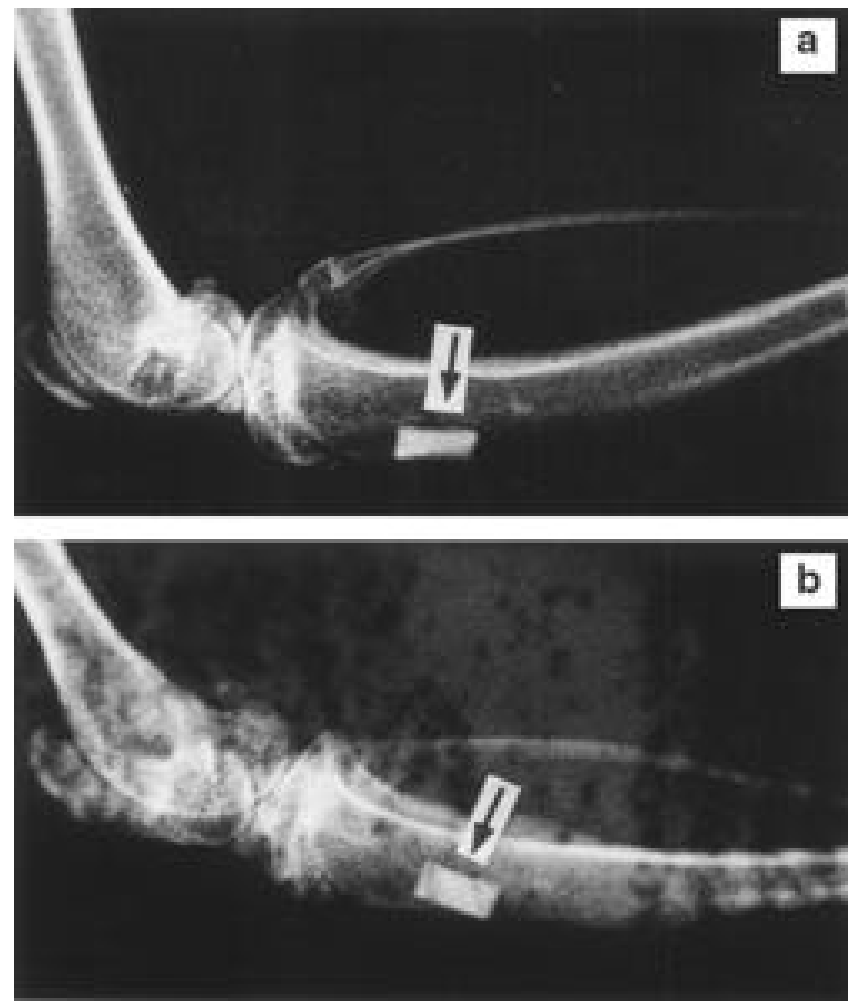

Figure 3. a and $\mathbf{b}$. X-ray radiographs of A-W glass ceramic block implanted group showing presence of $\mathrm{A}-\mathrm{W}$ block (arrow) at the site of implantation.
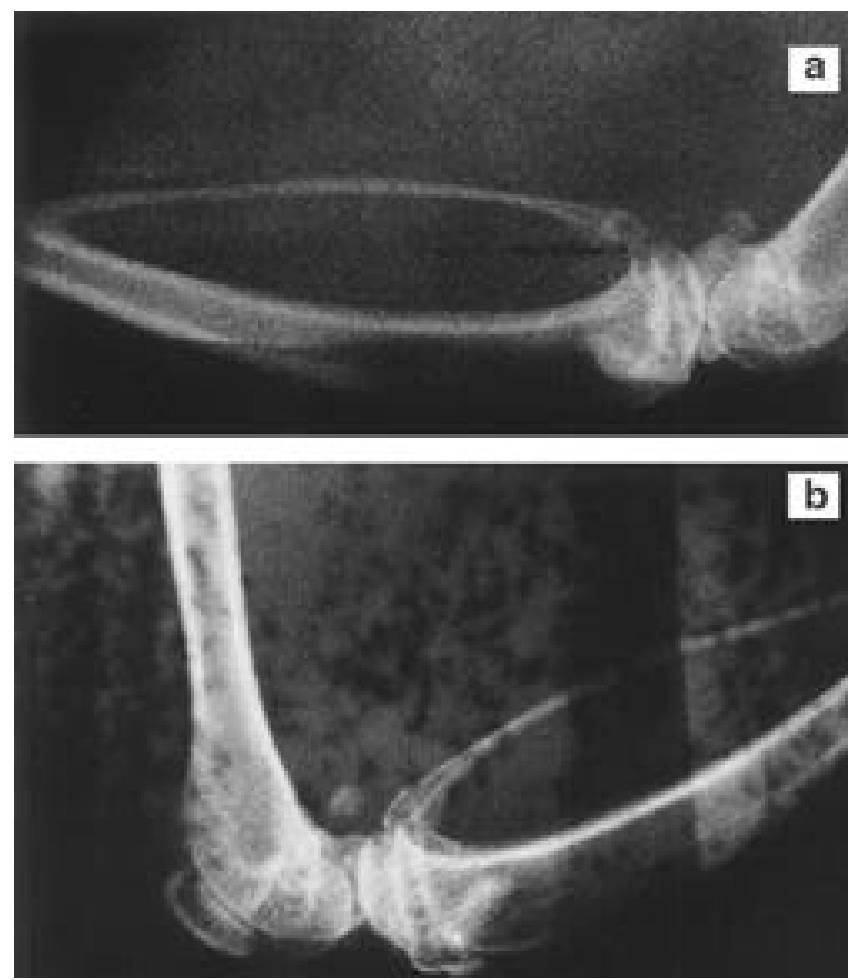

Figure 4. a and b. X-ray radiographs of $\mathrm{Ca}-\mathrm{P}-\mathrm{O}$ glass implanted group showing proper healing without any deformity or callous formation. the X-ray and histology observations it is evident that though the ceramic material is not absorbable in the body, it gives full support to the breached bone as evidenced even after six months of the surgical procedures. Since both the animals operated and implanted with the A-W glass ceramic blocks were alive for a long time without having fracture or any kind of deformity in bone, it can be concluded that the implanted material was in firm contact, giving enough strength to the bone to bear the animal weight.

Histology section of bone implanted with $\mathrm{Ca}-\mathrm{P}-\mathrm{O}$ glass is shown in figure 6. It showed that the bio-glass is absorbed by the body leaving behind very small island of $\mathrm{Ca}-\mathrm{P}-\mathrm{O}$ glass. The wound is healed completely with formation of new bone and marrow spaces. These observations indicate that $\mathrm{Ca}-\mathrm{P}-\mathrm{O}$ glass was almost

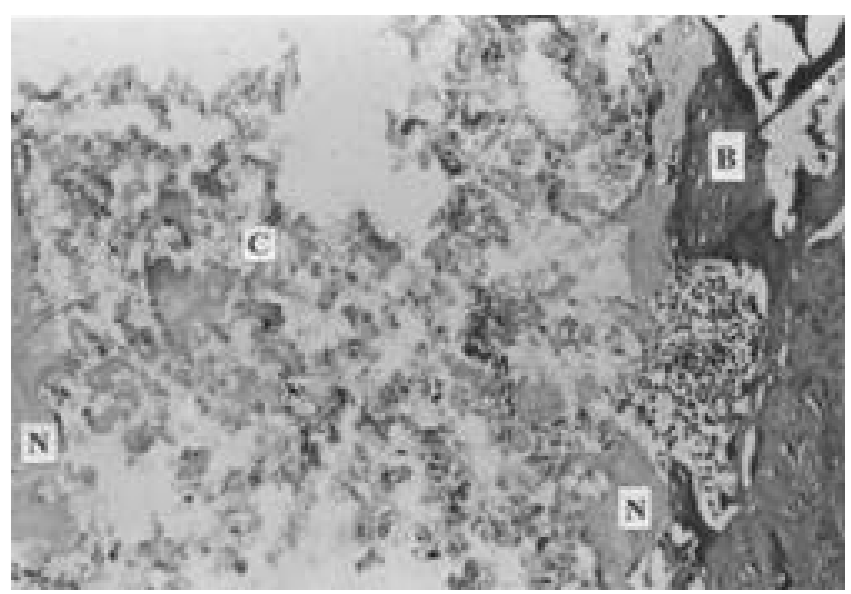

Figure 5. Photograph of histology section of A-W glass ceramic implanted group showing the implanted material still in created bone gap (B, old bone; $\mathrm{C}, \mathrm{A}-\mathrm{W}$ glass ceramic implant; $\mathrm{N}$, new bone).

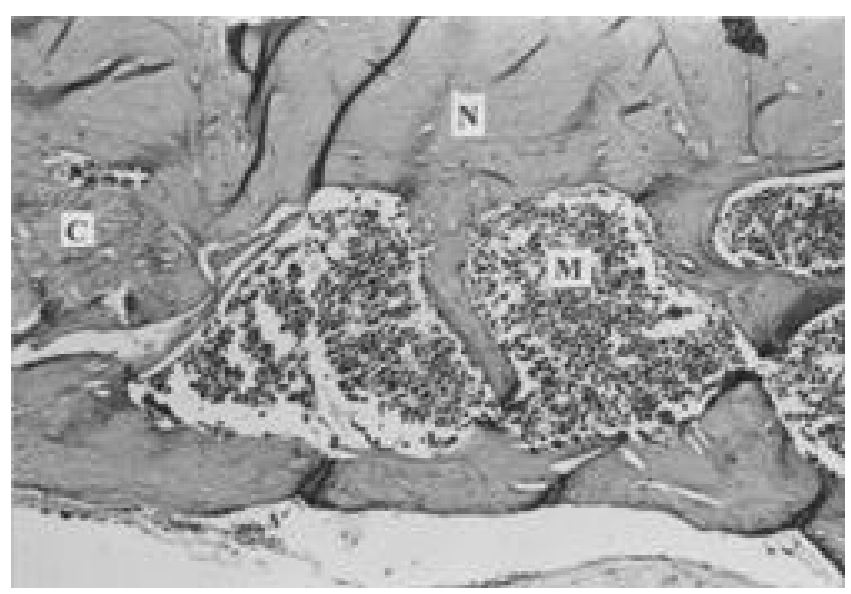

Figure 6. Photograph of histology section of $\mathrm{Ca}-\mathrm{P}-\mathrm{O}$ glass implanted group showing well healed bone wound leaving a small island of implanted material $(\mathrm{C}, \mathrm{Ca}-\mathrm{P}-\mathrm{O}$ implant material; $\mathrm{M}$, marrow spaces; $\mathrm{N}$, new bone). 
completely absorbed in the body and is replaced by the new bone growth without even leaving a callous. In both implants, biocompatibility is also suggested by the absence of inflammatory cells at the site or in the vicinity of the material.

\section{Acknowledgements}

The authors wish to thank J S Dubey, Material Science Division, BARC, Mumbai, for carrying out the 3-point bend test.

\section{References}

Chin T S, Wu D C, Hung M P and Wang C P 1996 J. Mater. Res. 11962
Coolidge B J and Howard R M 1979 in Animal histology procedures (Bethesda, Maryland, USA: US Dept. of Health, Education, and Welfare, Public Health Service, National Institute of Health, NIH Pub. No. 80-275) 2nd ed. p. 32

Engin N Ö and Taş A C $2000 \mathrm{~J}$. Am. Ceram. Soc. 831581

Fernandez E, Gil F J, Ginebra M P, Driessens F C M, Planell J A and Best S M 1999 J. Mater. Sci.: Mater. Med. 10169

Hench L L 1991 J. Am. Ceram. Soc. 741487

Jianguo Z, Xingdong Z, Müller-Mai C and Gross U 1994 J. Mater. Sci.: Mater. Med. 5243

LeGeros R Z, Trautz O R, LeGeros J P, Klein E and Shirra W P 1967 Science 1551409

McConnell D 1960 Am. Mineral. 45209

Nakamura T, Yamamuro T, Higashi S, Kukubo T and Itoo S 1985 J. Biomed. Mater. Res. 19685

Ritter S K 1997 Chem. \& Engg. News Aug. 25, p. 27

Suchanek W and Yoshimura M 1998 J. Mater. Res. 1394 
